\title{
MENINGKATKAN AKTIVITAS BELAJAR SISWA MELALUI MODEL ROLE PLAYING BERBASIS DIGITAL PADA PELAJARAN BAHASA INGGRIS DI SMP NEGERI 8 PADANGSIDIMPUAN
}

\author{
HASAN BAHRI, S.Pd. \\ NIP .19671012 1990031009 \\ Email: hasanbahri519@gmail.com
}

\begin{abstract}
abstrak
Pelaksanaan pembelajaran Bahasa Inggris di SMP Negeri 8 Padangsidimpuan masih menggunakan metode ceramah dan pemberian tugas yang belum dapat meningkatkan aktivitas dan hasil belajar. Yang menjadi permasalahan dalam penelitian ini adalah apakah penerapan model Role Playing Berbasis Digital dapat meningkatkan aktivitas dan hasil belajar siswa di kelas IX-2 manfaatnya diharapkan berguna bagi peneliti sebagai guru untuk meningkatkan proses pembelajaran dan hasil belajar Bahasa Inggris di SMP Negeri 8 Padangsidimpuan.

Aktivitas belajar dalam hal ini adalah yang menyangkut penerapan sebagian dari prinsipprinsip pembelajaran yang meliputi aktivitas bertanya, menjawab, menanggapi, menulis dan keseriusan sedangkan hasil belajar Bahasa Inggris merupakan prestasi atau nilai hasil belajar yang diperoleh siswa dalam satu materi ajar Bahasa Inggris. Role Playing Berbasis Digital adalah model pembelajaran yang diartikan sebagai model belajar yang melibatkan siswa lebih dominan pada proses belajar serta merangsang siswa untuk lebih banyak beraktivitas.

Yang menjadi subjek dari penelitian tindakan kelas ini adalah siswa kelas IX -2 SMP Negeri 8 Padangsidimpuan, pada tahun ajaran 2017/2018, yang terdiri dari 22 siswa yang sedang duduk pada semester 1 . Proses penelitian ini dilaksanakan sebanyak 3 siklus dan pada siklus I terdiri dari 2 pertemuan begitu juga pada siklus II terdiri dari 2 kali pertemuan dan pada siklus III terdiri dari 2 kali pertemuan.

Untuk mengumpulkan data, penelitian ini digunakan observasi /pengamatan oleh 2 orang observator yang dimana kedua orang observator tersebut adalah teman peneliti sebagai kolaborasi serta hasilnya dianalisis secara kualitatif.

Hasil penelitian ini menunjukkan bahwa ada peningkatan aktivitas dan hasil belajar dalam pembelajaran Bahasa Inggris di kelas IX-2 SMP Negeri 8 Padangsidimpuan pada tahun pelajaran 2017/2018. Hasil penelitian ini dapat disimpulkan bahwa penerapan model Role Playing Berbasis Digital dapat meningkatkan aktivitas belajar siswa yaitu yaitu $\mathbf{4 8 , 8 6 \%}$ pada siklus I menjadi $\mathbf{5 3 , 8 6 \%}$ pada siklus II dan naik menjadi $\mathbf{5 8 , 8 6 \%}$ pada siklus III.
\end{abstract}

\section{Kata-kata Kunci : 1. Pembelajaran Cooperative Script Berbasis TIK \\ 2. Aktivitas Belajar}

\section{PENDAHULUAN}

Pembelajaran merupakan proses menyiapkan peserta didik untuk melakukan aktivitas dalam rangka mencapai perubahan perilaku untuk mengaplikasikan tugas-tugas pembelajaran yang lebih kreatif supaya sasaran dan tujuan yang diharapkan dalam proses belajar mengajar lebih cepat tercapai. Untuk itu guru dituntut memiliki kompetensi yang maksimal dalam proses pembelajaran. Dengan kompetensi itu guru dapat mengembangkan karirnya sebagai guru yang baik serta dapat mengatasi berbagai kesulitan dalam proses pembelajaran.

Berdasarkan pengalaman penulis selama 26 tahun mengajarkan pelajaran Bahasa Inggris, pelajaran ini kurang diminati oleh sebahagian peserta didik. Rendahnya motivasi dan keaktifan siswa dalam belajar Bahasa Inggris telah lama menjadi bahan pikiran yang mengganggu penulis. Siswa menampakkan sikap yang kurang bergairah, kurang siap mengikuti pelajaran sehingga suasana kelas pasif. Umumnya siswa 
hanya mendengar saja penjelasan yang diberikan dalam proses penelitian sejak awal sampai saat pelajaran berlangsung. Siswa cenderung dengan hasil penelitian berupa laporan. Dengan tidak berani bertanya dan tidak terbiasa demikian, sejak perencanaan penelitian observer mengajukan gagasan yang bermanfaat. Sikap ini senantiasa terlibat, selanjutnya observer muncul karena perasaan takut salah, takut memantau, mencatat dan mengumpulkan data, ditertawakan atau mereka yang belum menguasai lalu menganalisis data serta terakhir dengan pelajaran yang diajarkan pada hal keberanian melaporkan hasil penelitian tersebut. PTK disini bertanya merupakan suatu aktivitas penting observer dituntut keterlibatannya secara langsung dalam proses pembelajaran.

Berdasarkan permasalahan tersebut di atas penulis menduga model pembelajaran serta pendekatan yang digunakan dalam pembelajaran selama ini belum efektif dimana penulis menggunakan metode ceramah lalu dilanjutkan dengan tanya jawab dan latihan. Penulis tidak memperhatikan bahwa kemampuan untuk menyerap informasi atau materi untuk setiap siswa berbeda, mengakibatkan hasil belajar yang bervariasi dan hasil rata-ratanya masih di bawah Kriteria Ketuntasan Minimal (KKM).

Melihat masalah di atas penulis mencoba mencari solusi dengan menerapkan Metode Discovery Untuk Meningkatkan Motivasi Dan Prestasi belajar Bahasa Inggris. Dengan metode ini diharapkan dapat meningkatkan motivasi dan keaktifan belajar siswa pada mata pelajaran Bahasa Inggris sehingga akhirnya prestasi belajar siswa dapat meningkat dengan signifikan.

Alasan pemilihan solusi ini adalah bahwa pada dasarnya penerapan metode discovery mempercepat tercapainya tujuan pembelajaran serta pemahaman siswa terhadap materi yang sedang dipelajari. Dengan pembelajaran metode discovery memungkinkan siswa tahu bagaimana caranya membaca dengan cepat, memahami bacaan, pemahaman terhadap materi, membantu mengorganisasikan dan dapat merekam informasi lisan dan tertulis serta yang paling penting adalah dapat mengkomunikasikan materi yang diharapkan dengan sesama teman sekelasnya.

\section{METODE PENELITIAN}

Jenis penelitian dalam penelitian ini adalah penelitian tindakan kelas (PTK) kolaborasi yang menggunakan desain penelitian kemmis dan Mc. Taggart.

Jenis penelitian ini adalah penelitian tindakan kelas ( PTK ) partisipan. " dimana orang melaksanakan penilian harus terlibat langsung dan terus menerus sejak awal sampai akhir penelitian " (Iskandar, 2011:27).

Desain PTK menurut Kemmis dan Taggart yaitu berbentuk spiral dari siklus yang satu ke siklus berikutnya. Konsep pokok penlitian tindakan menurut kemmis dan $\mathrm{Mc}$ Taggart terdapat tiga tahap rencana tindakan, meliputi: perencanaan (Planning), tindakan (acting) dan pengamatan (observing), dan Refleksi (reflecting) .

Penelitian dilaksanakan selama dua siklus dimana masing-masing siklus terdiri dari 3 kali

pertemuan dikenai perlakuan yang sama (alur

kegiatan yang sama). Setelah membahas satu pokok bahasan, diakhiri dengan formatif di akhir siklus dimaksudkan untuk memperbaiki sistem pengajaran yang telah dilaksanakan.

\section{HASIL PENELITIAN DAN PEMBAHASAN}

Hasil pengamatan dari observator pada siklus I adalah: Siswa yang mengajukan pertanyaan sebanyak 21 orang dengan jumlah aktifitas 40 dan persentase $45,45 \%$. Siswa yang memberikan jawaban sebanyak 22 orang dengan jumlah aktifitas 48 dan persentase 54,55\%. Siswa yang menanggapi atau memberi saran sebanyak 19 orang dengan jumlah aktifitas 41 dan persentase $46,59 \%$. Siswa yang menulis sebanyak 18 orang dengan jumlah aktifitas 42 dan persentase $47,73 \%$. Keseriusan siswa dalam mengikuti pembelajaran adalah sebanyak 19 orang siswa yang berperan aktif dalam kerja kelompok dengan jumlah aktifitas 44 dan dengan persentasi $50 \%$.

\section{Tabel 3}

Rekafitulasi Aktivitas Siswa Pada Pembelajaran Siklus I, Siklus II dan Siklus III

\begin{tabular}{|c|c|c|c|c|c|c|}
\hline \multirow{2}{*}{$\begin{array}{l}\mathrm{N} \\
\mathrm{O}\end{array}$} & \multirow{2}{*}{$\begin{array}{c}\text { AKTIVIT } \\
\text { AS }\end{array}$} & \multicolumn{3}{|c|}{$\begin{array}{l}\text { S I K L } \\
\text { U S }\end{array}$} & \multirow{2}{*}{$\begin{array}{l}\text { JU } \\
\text { ML } \\
\text { AH }\end{array}$} & \multirow{2}{*}{$\begin{array}{c}\text { Persen } \\
\text { tase }\end{array}$} \\
\hline & & I & II & $\begin{array}{c}\text { II } \\
\text { I }\end{array}$ & & \\
\hline 1 & Bertanya & $\begin{array}{l}4 \\
0\end{array}$ & $\begin{array}{l}4 \\
5\end{array}$ & $\begin{array}{l}5 \\
1\end{array}$ & 136 & $\begin{array}{c}51,51 \\
\%\end{array}$ \\
\hline 2 & $\begin{array}{l}\text { Menja } \\
b\end{array}$ & $\begin{array}{l}4 \\
8\end{array}$ & $\begin{array}{l}5 \\
0\end{array}$ & $\begin{array}{l}5 \\
2\end{array}$ & 150 & $\begin{array}{c}56,82 \\
\%\end{array}$ \\
\hline
\end{tabular}




\begin{tabular}{|c|c|c|c|c|c|c|}
\hline 3 & $\begin{array}{l}\text { Menangg } \\
\text { api }\end{array}$ & $\begin{array}{l}4 \\
1\end{array}$ & $\begin{array}{l}4 \\
6 \\
\end{array}$ & $\begin{array}{l}5 \\
0 \\
\end{array}$ & 137 & $\begin{array}{c}51,88 \\
\%\end{array}$ \\
\hline 4 & Menulis & $\begin{array}{l}4 \\
2\end{array}$ & $\begin{array}{l}4 \\
8\end{array}$ & $\begin{array}{l}5 \\
2\end{array}$ & 142 & $\begin{array}{c}53,79 \\
\%\end{array}$ \\
\hline 5 & $\begin{array}{l}\text { Keseriusa } \\
\mathrm{n}\end{array}$ & $\begin{array}{l}4 \\
4 \\
\end{array}$ & $\begin{array}{l}4 \\
8 \\
\end{array}$ & $\begin{array}{l}5 \\
3 \\
\end{array}$ & 145 & $\begin{array}{c}54,92 \\
\%\end{array}$ \\
\hline & mlah Skor & $\begin{array}{l}2 \\
1 \\
5\end{array}$ & $\begin{array}{l}2 \\
3 \\
7\end{array}$ & $\begin{array}{l}2 \\
5 \\
8\end{array}$ & 710 & $\begin{array}{c}268,92 \\
\%\end{array}$ \\
\hline & ersentasi & $\begin{array}{l}4 \\
8, \\
8 \\
6 \\
\end{array}$ & $\begin{array}{l}5 \\
3, \\
8 \\
7\end{array}$ & $\begin{array}{l}5 \\
8, \\
6 \\
4\end{array}$ & $\begin{array}{r}161 \\
, 37\end{array}$ & $\begin{array}{c}53,79 \\
\%\end{array}$ \\
\hline & $\begin{array}{l}\text { Rata-Rata } \\
\text { (Skor) }\end{array}$ & $\begin{array}{l}1, \\
9 \\
5\end{array}$ & $\begin{array}{l}2, \\
1 \\
5\end{array}$ & $\begin{array}{l}\mathbf{2}, \\
\mathbf{3} \\
\mathbf{5}\end{array}$ & $\begin{array}{c}6,4 \\
5\end{array}$ & 2,15 \\
\hline
\end{tabular}

\begin{tabular}{|c|l|c|c|}
\cline { 3 - 4 } O & PENGAMATAN & $\begin{array}{l}\text { Jumlah } \\
\text { Skor } \\
\text { Aktivita } \\
\text { s }\end{array}$ & $\begin{array}{c}\text { Persenta } \\
\text { se }\end{array}$ \\
\hline 1 & $\begin{array}{l}\text { Mengajukan } \\
\text { pertanyaan }\end{array}$ & 45 & $51,14 \%$ \\
\hline 2 & $\begin{array}{l}\text { Memberikan } \\
\text { jawaban }\end{array}$ & 50 & $56,82 \%$ \\
\hline 3 & Menaggapi & 46 & $52,27 \%$ \\
\hline 4 & Menulis & 48 & $54,55 \%$ \\
\hline 5 & Keseriusan & 48 & $54,55 \%$ \\
\hline \multicolumn{2}{|c|}{ JUMLAH } & 237 & 269,32 \\
$\%$
\end{tabular}

1. Analisis Data Aktivitas Belajar Siklus I Jumlah Siswa : 22 orang

\begin{tabular}{|c|c|c|c|}
\hline \\
\hline \multirow[b]{2}{*}{ NO } & \multirow[b]{2}{*}{$\begin{array}{c}\text { KATEGORI } \\
\text { PENGAMATAN }\end{array}$} & \multicolumn{2}{|c|}{ AKTIVITAS } \\
\hline & & $\begin{array}{c}\text { Jumlah } \\
\text { Skor } \\
\text { Aktivita } \\
\text { s }\end{array}$ & $\begin{array}{c}\text { Persen } \\
\text { tase }\end{array}$ \\
\hline 1 & \begin{tabular}{|l|}
$\begin{array}{l}\text { Mengajukan } \\
\text { pertanyaan }\end{array}$ \\
\end{tabular} & 40 & 45,45 \\
\hline 2 & $\begin{array}{l}\text { Memberikan } \\
\text { jawaban }\end{array}$ & 48 & 54,55 \\
\hline 3 & Menaggapi & 41 & 46,56 \\
\hline 4 & Menulis & 42 & 47,73 \\
\hline 5 & Keseriusan & 44 & 50,00 \\
\hline \multicolumn{2}{|r|}{ JUMLAH } & 215 & 244,32 \\
\hline \multicolumn{2}{|r|}{ RATA-RATA } & & 48,86 \\
\hline
\end{tabular}

\section{Analisis Data Aktivitas Belajar Siklus III}

Sama halnya dengan siklus I dan siklus II aktivitas belajar siswa pada siklus III ini juga ditinjau dari 5 kategori yaitu : 1) aktivitas mengajukan pertanyaan, 2) aktivitas memberikan jawaban, 3) aktivitas menaggapi, 4) aktivitas menulis dan 5) aktivitas mental yang berupa keseriusan belajar. Masing-masing kategori mendapat nilai 1 sampai 4 . Untuk melihat besarnya persentase aktivitas siswa dari kelima aktivitas tersebut pada pembelajaran Siklus II penulis sajikan pada tabel berikut ini :

\begin{tabular}{|c|c|c|c|}
\hline \multirow[b]{2}{*}{$\begin{array}{l}\mathrm{N} \\
\mathrm{O}\end{array}$} & \multirow[b]{2}{*}{$\begin{array}{c}\text { KATEGORI } \\
\text { PENGAMATAN }\end{array}$} & \multicolumn{2}{|c|}{ AKTIVITAS } \\
\hline & & $\begin{array}{c}\text { Jumlah } \\
\text { Skor } \\
\text { Aktivita } \\
\text { s }\end{array}$ & $\begin{array}{l}\text { Persenta } \\
\text { se }\end{array}$ \\
\hline 1 & $\begin{array}{l}\text { Mengajukan } \\
\text { pertanyaan }\end{array}$ & 51 & $57,95 \%$ \\
\hline 2 & $\begin{array}{l}\text { Memberikan } \\
\text { jawaban }\end{array}$ & 52 & $59,09 \%$ \\
\hline 3 & Menaggapi & 51 & $57,95 \%$ \\
\hline 4 & Menulis & 52 & $59,09 \%$ \\
\hline 5 & Keseriusan & 53 & $60,23 \%$ \\
\hline & JUMLAH & 259 & $\begin{array}{c}294,32 \\
\%\end{array}$ \\
\hline & RATA-RATA & 2,35 & $58,86 \%$ \\
\hline
\end{tabular}

\section{Analisis Data Aktivitas Belajar Siklus II}

Sama halnya dengan siklus I aktivitas belajar siswa pada siklus II ini juga ditinjau dari 5 kategori yaitu : 1) aktivitas mengajukan pertanyaan, 2) aktivitas memberikan jawaban, 3) aktivitas menaggapi, 4) aktivitas menulis dan 5) aktivitas mental yang berupa keseriusan belajar. Masing-masing kategori mendapat nilai 1 sampai 4 . Untuk melihat besarnya persentase aktivitas siswa dari kelima aktivitas tersebut pada pembelajaran Siklus II penulis sajikan pada tabel berikut ini:

Jumlah Siswa : 22 orang

\begin{tabular}{|l|l|l|}
\hline $\mathrm{N}$ & KATEGORI & AKTIVITAS \\
\hline
\end{tabular}

\section{PEMBAHASAN}


Sejalan dengan hasil penelitian tindakan kelas sebagaimana yang dipaparkan di atas ada beberapa hal yang perlu dilihat terutama yang menyangkut tujuan dari penilitan ini yaitu meningkatkan aktivitas belajar siswa pada pembelajaran Bahasa Inggris dengan penerapan model Role Playingr Berbasis Digital.

Kalau dilihat dari angka yaitu $\mathbf{4 8 , 8 6 \%}$ pada siklus I menjadi $\mathbf{5 3 , 8 6 \%}$ pada siklus II dan naik menjadi $\mathbf{5 8 , 8 6 \%}$ pada siklus III. Hal ini jelas telah ada perubahan proses pembelajarannya. Karena hasil aktivitas siswapun menunjukkan naik yang konsekuensinya kalau aktivitas siswa pada proses pembelajarannya mengalami kenaikan atau berkualitas tentu hasilnya berdampak positif.

Model Role Playing Berbasis Digital dapat menciptakan suasana belajar jauh lebih dinamis dan lebih demokratis karena semua siswa dilibatkan untuk berpikir bagaimana cara yang sesuai dengan keinginan mereka agar proses pembelajaran dapat lebih baik. Guru bukanlah semata-mata sebagai sosok figur guru tetapi juga sebagai sosok teman belajar.

Selanjutnya, dalam penerapan Role Playing Digital yang telah dilakukan pada penelitian tindakan ini, ada beberapa hal yang perlu diperhatikan terutama penerapan skenarionya. Di antaranya adalah pergantian teman satu kelompok dan ketua kelompok merupakan sesuatu teknik untuk menghindari kebosanan siswa. Di samping itu ada gejala bahwa siswa yang belum menjadi ketua kelompok merasa terdorong untuk mampu menjadi ketua kelompok. Hal ini diketahui bahwa mereka mengusulkan agar untuk pertemuan selanjutnya diadakan pergantian teman sekelompok dan ketua kelompok.

Masalah hasil belajar kognitif menunjukkan bahwa ada peningkatan dari siklus I setelah menerapkan Role Playing Berbasis Digital. Ini diindikasikan dengan adanya perubahan metode/model mengajar dari yang bersifat konversional yaitu ceramah dan pemberian tugas menjadi metode Role Playing Berbasis Digital.

Tabel : 7

Perbandingan Hasil Aktivitas Siswa dan Nilai Kognitif Siswa

Pada Pembelajaran Siklus I, Siklus II dan Siklus

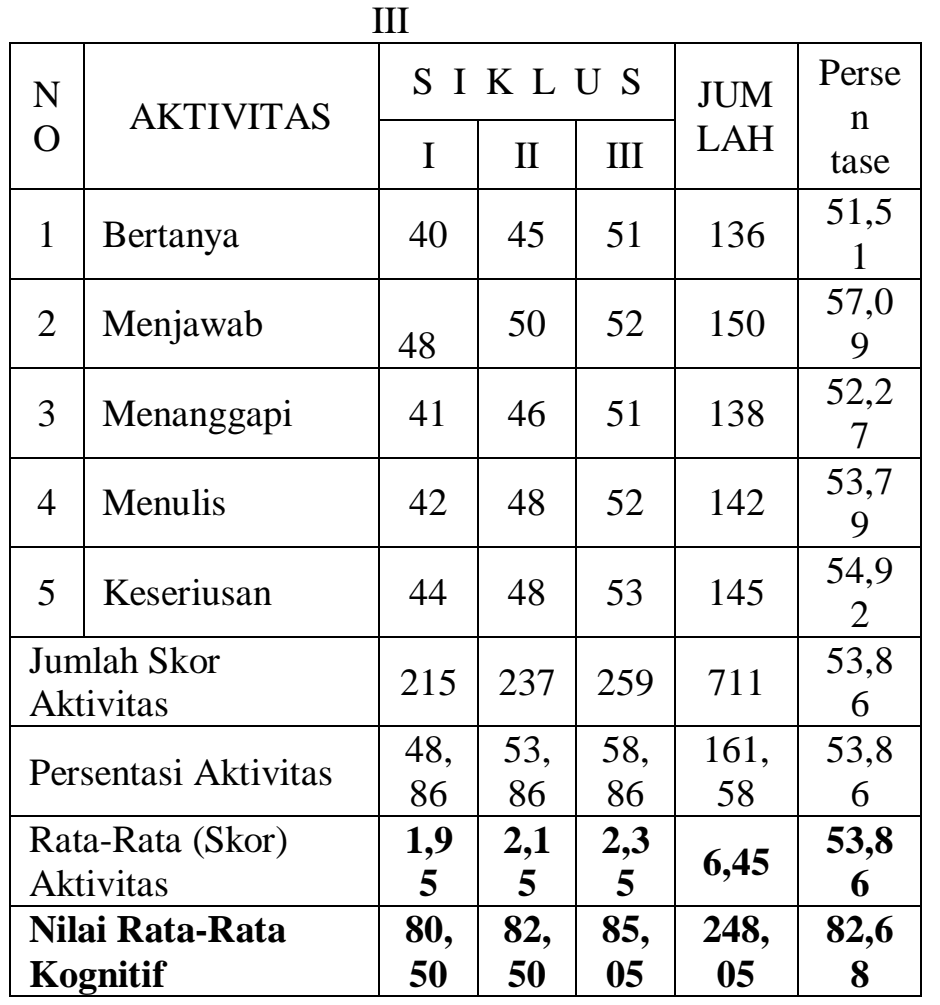

\section{KESIMPULAN}

Berdasarkan hasil penelitian sebagaimana yang dipaparkan dalam $\mathrm{BAB}$ IV, dapatlah disimpulkan bahwa :

1. Ada peningkatan aktivitas belajar siswa $\begin{array}{lllll}\text { kelas IX-2 SMP Negeri } 8 & \end{array}$ Padangsidimpuan pada pembelajaran Bahasa Inggris Tahun Pelajaran 2017/2018 dengan penerapan model pembelajaran Role Playing Berbasis Digital yaitu 48,86\% (Cukup) pada siklus I menjadi $\mathbf{5 3 , 8 6 \%}$ (Baik) pada siklus II dan naik menjadi $\mathbf{5 8 , 8 6 \%}$ (Baik) pada siklus III.

2. Ada peningkatan hasil belajar siswa kelas IX-2 SMP Negeri 8 Padangsidimpuan pada pembelajaran Bahasa Inggris Tahun Ajaran 2017/2018 melalui penerapan model pembelajaran Role Playing Berbasis Digital yang dikategorikan "Baik". Hal ini dilihat dari rata-rata nilai kemampuan siswa siklus I adalah 80,50 sementara nilai rata-rata yang diperoleh siswa pada siklus II adalah 82,50 serta nilai rata - rata siswa pada siklus III adalah 85,05. 


\section{DAFTAR PUSTAKA}

Azhar Arsyad, Media Pembelajaran, Jakarta :

PT Raja Grapindo Persada, 2007.

Davis, Ivor K, (penerjemah : Sudarsono S, dkk.),

Pengelolaan Belajar, Jakarta: C. V. Rajawali dan PAU-UT, 1987.

Dimyati dan Mudjiono, Belajar dan

Pembelajaran, Jakarta : Rineka Cipta, , 2002

Dirjen Manajemen Pendidikan Dasar dan Menengah, Panduan Pengembangan Bahan Ajar Berbasis TIK, Jakarta :2010

Dirjen Manajemen Pendidikan Dasar dan Menengah, Pedoman Memilih dan Menyusun Bahan Ajar, Jakarta :2006

Dirjen Peningkatan Mutu Pendidik dan Tenaga Kependidikan Depdiknas, Penilaian Hasil Belajar, Jakarta :2008

Djamarah Syaiful Bahri, Guru dan Anak Didik,

Jakarta : Rineka Cipta, 2000.

Hamalik Oemar, Kurikulum dan Pembelajaran, Jakarta : Bumi Aksara, 2003.

Nana Sujana, Dasar-Dasar Proses Belajar Mengajar, Bandung : Sinar Baru, 1991.

Nana Sudjana, Penilaian Hasil Proses Belajar Mengajar. Bandung: Remaja Rosdakarya, 2006..

Nana Sudjana, R. Ibrahim, Penelitian dan Penilaian Pendidikan. Ban-dung: Sinar Baru, 2000.

Sagala Syaiful, Konsep dan Makna

Pembelajaran, Bandung : Alfabet, 2005.

Sardiman, A.M, Interaksi dan Motivasi Belajar Mengajar, Jakarta : PT Raja Grafindo Persada, 2009.

Slameto, Belajar dan Faktor - faktor yang Mempengaruhinya, Jakarta : Rineka Cipta, 1991.

Suharsimi Arikunto, Penelitian Tindakan Kelas, Jakarta : Bumi Aksara, 2008,

Suharsimi Arikunto, Prosedur Penelitian Suatu Pendekatan Praktek, Jakarta : Rineka Cipta, 2002.

Suhertian, A. Piet, Prinsip dan Tekhnik Supervisi Pendidikan, Surabaya : Usaha Nasional, 1981.

Suparman, Atwi, Model-Model Pembelajaran Interaktif, Jakarta : STA LAN Press, 1997.

Syah Muhibbin, Psikologi dengan Pendekatan Baru, Bandung : Remaja Rosdakarya,2005. 
Volume 3 Nomor 2, Halaman 1-77, Juli-Desember 2018

RISTEKDIK / Jurnal Bimbingan dan Konseling

P-ISSN: 2527-4244, E-ISSN : 2541-206X 